\title{
Different Mechanisms Generate Maintained Activity in ON and OFF Retinal Ganglion Cells
}

\author{
David J. Margolis ${ }^{1,2}$ and Peter B. Detwiler ${ }^{1,2}$ \\ ${ }^{1}$ Program in Neurobiology and Behavior and 2Department of Physiology and Biophysics, University of Washington, Seattle, Washington 98195
}

\begin{abstract}
Neuronal discharge is driven by either synaptic input or cell-autonomous intrinsic pacemaker activity. It is commonly assumed that the resting spike activity of retinal ganglion cells (RGCs), the output cells of the retina, is driven synaptically, because retinal photoreceptors and second-order cells tonically release neurotransmitter. Here we show that ON and OFF RGCs generate maintained activity through different mechanisms: $0 \mathrm{~N}$ cells depend on tonic excitatory input to drive resting activity, whereas OFF cells continue to fire in the absence of synaptic input. In addition to spontaneous activity, OFF cells exhibit other properties of pacemaker neurons, including subthreshold oscillations, burst firing, and rebound excitation. Thus, variable weighting of synaptic mechanisms and intrinsic properties underlies differences in the generation of maintained activity in these parallel retinal pathways.
\end{abstract}

Key words: spontaneous activity; dendrites; retinal ganglion cell; light; pacemaker; receptive field

\section{Introduction}

A common characteristic of neural circuits is that they are active even at rest. The maintained or resting discharge of neurons is determined by a combination of synaptic input and intrinsic electrophysiological properties (Harris-Warrick, 2002; Hausser et al., 2004; Surmeier et al., 2005). These factors are weighted differently in different neural circuits. In some neurons (e.g., cortical pyramidal cells), maintained activity requires synaptic input (Cowan and Wilson, 1994; Sanchez-Vives and McCormick, 2000; Petersen et al., 2003), whereas in other cells (e.g., cerebellar Purkinje cells), it is driven primarily by the intrinsic pacemaker properties of the neuron itself (Hausser and Clark, 1997; Raman and Bean, 1999). Information about the synaptic and intrinsic mechanisms that underlie resting discharge in the output cells of a neural circuit is critical for understanding how the circuit functions.

The neural circuitry of the retina processes images projected on the photoreceptor mosaic and relays visual information to the brain through changes in the spike activity of retinal ganglion cells (RGCs). These are the output cells of parallel retinal pathways specialized for detection of different features in a visual image (Masland, 2001; Wassle, 2004). Changes in light intensity, central to our continuous experience of vision, are encoded by separate ON and OFF pathways, two major channels in the visual system that are excited by light onset and offset, respectively (Werblin and Dowling, 1969; Schiller, 1992). The push-pull

Received Jan. 11, 2007; revised April 10, 2007; accepted April 28, 2007.

This work was supported by National Institutes of Health Grant EY02048 (P.B.D.) and Predoctoral Training Grant GM07108 (D.J.M.). We thank Winfried Denk and Thomas Euler for help with two-photon image acquisition and analysis, Fred Rieke and Gabe Murphy for comments on a previous draft of this manuscript, Jill Jensen for participation in initial experiments, and Paul Newman for technical assistance.

Correspondence should be addressed to David J. Margolis, University of Washington, Box 357290, Seattle, WA 98195. E-mail: dmargoli@u.washington.edu.

DOI:10.1523/JNEUROSCI.0130-07.2007

Copyright $\odot 2007$ Society for Neuroscience $\quad$ 0270-6474/07/275994-12\$15.00/0 modulation of firing rate from ON and OFF RGCs is thought to underlie perception of changes in contrast, the "highlights and shadows" in a visual scene (Schiller et al., 1986; Nelson and Kolb, 2004).

The resting discharge of RGCs is thought to reflect the balance of excitatory and inhibitory synaptic input the cell receives from the excitatory center and antagonistic surround regions of its receptive field (Kuffler et al., 1957; Rodieck, 1967; Barlow and Levick, 1969; Sakmann and Creutzfeldt, 1969; Frishman and Levine, 1983). Differences in the resting discharge of ON and OFF RGCs were described in early work (Barlow and Levick, 1969; Barlow et al., 1971) but have not yet been fully explained. Studies comparing the synaptic circuitry of $\mathrm{ON}$ and OFF pathways identified differences in the strength and dynamics of excitatory and inhibitory synaptic input (Pang et al., 2003; Zaghloul et al., 2003; Murphy and Rieke, 2006; Sagdullaev et al., 2006), resulting in the presumption that differences between ON and OFF RGCs arise solely from differences in their underlying synaptic circuitry.

The possibility that there are also intrinsic differences in the electrophysiological properties of ON and OFF RGCs has not been directly tested. To investigate this, we studied the firing properties of ON and OFF RGCs in the absence of synaptic input. We find that OFF cells, unlike ON cells, generate spontaneous activity that is not driven by synaptic input. In addition, these cells show distinguishing differences in burst firing, subthreshold oscillations, rebound excitation, and voltage-dependent $\mathrm{Ca}^{2+}$ and $\mathrm{Na}^{+}$conductances. These results highlight different mechanisms for generating maintained firing in $\mathrm{ON}$ and $\mathrm{OFF}$ retinal circuits.

\section{Materials and Methods}

Animals and tissue preparation. All experimental protocols were approved by the Administrative Panel on Laboratory Animal Care at the University of Washington. After the animals were killed by cervical dislocation, the eyes from adult (5-8 weeks) male wild-type C57BL/6 mice (The Jackson Laboratory, Bar Harbor, ME) were enucleated and placed 
in room-temperature Ames' medium (Sigma, St. Louis, MO) equilibrated with $5 \% \mathrm{CO}_{2} / 95 \% \mathrm{O}_{2}$. Eyes were hemisected, and retinas were isolated intact from the retinal pigment epithelium and then adhered photoreceptor-side down onto translucent Anodisc filter paper (Whatman, Florham Park, NJ) by wicking away excess solution. The recording chamber was placed on the stage of a custom-built two-photon laserscanning fluorescence microscope and viewed with a CCD camera using infrared illumination. The retina was perfused with warmed $\left(30-34^{\circ} \mathrm{C}\right)$ equilibrated Ames' medium at a flow rate of $5-8 \mathrm{ml} / \mathrm{min}$.

For experiments that required light responses, animals were housed in a light-tight chamber for $2-15 \mathrm{~h}$ before experiments, and dissections were performed in the dark using infrared illumination and image converters. For experiments in which we applied synaptic blockers (see below), which rendered the retina insensitive to light, animals were not dark adapted beforehand, and dissections were performed in dim room light using a standard light microscope.

Electrophysiology and light stimuli. Cells in the ganglion cell layer were targeted for patch-clamp recording based on their large $(20-25 \mu \mathrm{m})$ diameter somata, which were exposed by microdissecting the internal limiting membrane above the cell of interest using an empty patch pipette. The exposed cell was recorded in either current- or voltage-clamp mode with a patch electrode (3-7 M $\Omega$ ) filled with an internal solution that contained the following (in mM): $120 \mathrm{~K}$-gluconate, $5 \mathrm{NaCl}, 5 \mathrm{KCl}, 5$ HEPES, $1 \mathrm{MgCl}_{2}$, 1 ATP, 0.1 GTP, and 0.14 Oregon Green 488 BAPTA-1 (OGB-1) adjusted to $\mathrm{pH} 7.4$ with $\mathrm{KOH}$. Series resistance was minimized, and recordings were discarded if they were $>15 \mathrm{M} \Omega$. Voltages were corrected for a $10 \mathrm{mV}$ liquid junction potential that was determined experimentally (Neher, 1992). Signals were amplified with an Axopatch 200B amplifier (Molecular Devices, Palo Alto, CA), and data were acquired and analyzed off-line using custom routines written in Igor Pro (WaveMetrics, Lake Oswego, OR).

Visual stimuli were generated by a digital projector (VistaGRAPHX 2500; Christie Digital, Wokingham, UK) controlled by custom software through a VSG3 stimulus generator (Cambridge Research Systems, Kent, UK) (Packer et al., 2001). Stimuli were focused through a substage condenser onto the photoreceptor layer of the retina. All stimuli were spots centered over the receptive field of the cell.

Synaptic antagonists. To block synaptic transmission, neurotransmitter receptor antagonists were added to the extracellular solution. The standard synaptic blockers mixture contained the following (in $\mu \mathrm{M}$ ): 50 L-APB, 20 CNQX, 50 APV, 1 strychnine, and 50 picrotoxin (see Figs. 3-9). In additional experiments (in $\mu \mathrm{M}$ ), 0.1 TTX (see Figs. 8, 9), 100 $\mathrm{NiCl}_{2}$ (see Fig. 7), 50 (2S)-3-[(15)-1-(3,4-dichlorophenyl)ethyl]amino2-hydroxypropyl)(phenylmethyl)phosphinic acid (CGP 55845), $50 \mathrm{cu}$ rare, 100 carbenoxelone, $300 \mathrm{CdCl}_{2}, 20$ nimodipine, or 20 nifedipine (data not shown) were added to the blockers mixture. Chemicals were purchased from Sigma or Tocris (Ellisville, MO).

Two-photon microscopy. Retinal ganglion cells that had been filled with a fluorescent $\mathrm{Ca}^{2+}$ indicator (OGB-1) via diffusion from the recording pipette and the interstitial spaces in the retina that had been counterstained with extracellular sulforhodamine-101 ( $\sim 0.1 \mathrm{~mm}$; Sigma) were imaged simultaneously using a custom-built multiphoton fluorescence microscope (Denk et al., 1990; Denk and Detwiler, 1999; Euler et al., 2002). The two-photon excitation source was a mode-locked titanium/ sapphire laser (Mira-900; Coherent, Santa Clara, CA) tuned to $930 \mathrm{~nm}$. Fluorescence was collected by a $60 \times$ water immersion imaging objective (1.0 numerical aperture; Nikon, Tokyo, Japan) and directed to two independent photomultiplier detectors that measured the light passing through either a $535 \mathrm{~nm}$ (50 nm bandpass) filter ("green channel," calcium indicator signal) or a $622 \mathrm{~nm}$ (36 nm bandpass) filter ("red channel," sulforhodamine signal) (fluorescence emission filters from Chroma Technology, Rockingham, VT). The microscope used CfNT imaging software originally written at Bell Labs (Murray Hill, NJ) by R. Stepnoski and modified extensively by M. Müller at the Max Planck Institute for Medical Research in Heidelberg, Germany. $Z$-stack image series $(256 \times$ 256 pixels) were acquired at $1.95 \mathrm{~Hz}$ and analyzed off-line using either custom software (Igor Pro) written by Thomas Euler or NIH ImageJ (http://rsb.info.nih.gov/ij/).

Data analysis. Resting potential $\left(V_{\text {rest }}\right)$ was defined as the mean mem- brane potential $\left(V_{\mathrm{m}}\right)$ measured over $1-5 \mathrm{~s}$. For recordings in which the cell was spiking, spikes were digitally removed $(2 \mathrm{~ms}$ deleted after $10 \mathrm{~V} / \mathrm{s}$ threshold) before measuring $V_{\text {rest }}$. In Figure 8, $V_{\text {rest }}$ was defined as mean $V_{\mathrm{m}}$ in synaptic blockers plus $0.1 \mu \mathrm{M}$ TTX.

The coefficient of variation $(\mathrm{CV}=\mathrm{SD} /$ mean $)$ was used to measure variability in spike trains (see Fig. 4) and voltage oscillations (see Fig. 5). For spike trains, CV of the interval between successive spikes [the interspike interval (ISI)] was measured. For voltage oscillations, CV was measured from 100-400 ms segments of raw voltage traces. In both cases, CV was plotted versus $V_{\mathrm{m}}$, which was measured as the mean voltage over the last $100-300 \mathrm{~ms}$ of responses to negative current steps after $V_{\mathrm{m}}$ had stabilized.

Persistent $\mathrm{Na}^{+}$current $\left(I_{\mathrm{NaP}}\right)$ was measured using slow voltage ramp stimuli (see Fig. 8), standard procedures for measuring this current (Stafstrom et al., 1985; Crill, 1996; Pennartz et al., 1997; Powers and Binder, 2003). Currents in response to $5 \mathrm{~s}$ voltage ramps from -90 to $-10 \mathrm{mV}(16 \mathrm{mV} / \mathrm{s})$ were measured in the presence of synaptic blockers before and after $0.1 \mu \mathrm{M}$ TTX. $I_{\mathrm{NaP}}$ was taken as the TTX-subtracted current (blockers-TTX). Activation voltage $\left(V_{\text {activ }}\right)$ was defined as the voltage corresponding to $5 \%$ maximum current.

All data are presented as mean \pm SEM. Unpaired $t$ tests were used for group comparisons unless stated otherwise. Statistical significance was indicated as ${ }^{\star} p<0.05$ and ${ }^{\star *} p<0.01$.

\section{Results}

\section{Cell identification: physiology}

In the isolated, intact flat-mount mouse retina, we targeted cells with large $(20-25 \mu \mathrm{m})$ somas in the ganglion cell layer for patchclamp recording. These cells had a high probability of being classified as ON, OFF transient (OFF T), or OFF sustained (OFF S) RGCs, as reported previously in mouse retina (Pang et al., 2003; Murphy and Rieke, 2006). We identified cells using both physiological and morphological criteria. Figure $1 A$ illustrates representative responses to light from each type of cell. In the darkadapted retina, the onset of a step of light excites ON cells (Fig. $1 A$, left) and inhibits OFF T and OFF S, which in both cases are excited at the termination of the light stimulus (Fig. $1 A$, middle, right). OFF $\mathrm{T}$ cells could be distinguished from OFF $\mathrm{S}$ cells by generating a higher-frequency burst of spikes at light offset (often $>300 \mathrm{~Hz}$ ) than the OFF S cells (typically $<100 \mathrm{~Hz}$ ). These results are consistent with recent studies that found similar cell types in mouse retina (Pang et al., 2003; Murphy and Rieke, 2006).

\section{Cell identification: morphology}

All recorded cells were filled with OGB-1, and their morphology was visualized using two-photon florescence microscopy to take serial images at different focal depths in the retina $(Z$-series stack). Figure $1 B$ shows $Z$-projections of image stacks of representative ON (left), OFF T (middle), and OFF S (right) RGCs. At the same time fluorescence images of the cell were being taken, the retina was perfused with Ames' solution containing $\sim 0.1 \mathrm{~mm}$ sulforhodamine-101, a membrane-impermeant fluorescent counterstain that fills the interstitial space (Denk and Detwiler, 1999; Euler et al., 2002). Image stacks of the recorded cell and the extracellular space surrounding it were collected simultaneously using the green and red detector channels of the microscope, respectively. Nine images of $Z$-stacks of 33 images showing the OFF $T$ cell in Figure $1 B$ and the extracellular counterstain at identical focal planes are shown in $C$. The images of the sulforhodamine-101 counterstain were used to identify the boundaries of the inner plexiform layer (IPL). The proximal bor$\operatorname{der}(\mathrm{IPL}=0 \%)$ was defined as the first image after the RGC layer to contain no somata (black asterisk), and the distal border (IPL $=100 \%$ ) was defined as the last image to contain no somata before the inner nuclear layer (white asterisk). Borders identified 
by eye in this manner could be verified in side projections of red channel image stacks (Fig. 1C1, right) and/or by plotting intensity of red fluorescence in each image versus focal depth (Fig. $1 D$, circles).

The dendritic arbors of ON, OFF T and OFF $S$ cell types stratified at distinct depths within the IPL. The intensity of green channel (OGB-1) fluorescence in each image in a $Z$-series was measured and plotted against IPL depth (Fig. $1 D$, triangles). The stratification level was defined as the peak of a smoothed curve drawn through the points. For the OFF T cell in Figure $1 D$, stratification was at $61 \%$ of the IPL depth. Measurements from a collection of ON, OFF T, and OFF S cells show that the dendrites of the three cell types stratify at different levels in IPL without overlapping (Fig. $1 E$ ). These results indicate that ON, OFF T, and OFF S RGCs are morphologically as well as physiologically distinct. The differences in dendritic stratification were used to identify cell types in experiments in which the light sensitivity of the retina was abolished by using a mixture of synaptic blockers (see below).

\section{Maintained activity}

Although the existence of maintained firing in $\mathrm{ON}$ and OFF RGCs has been known for decades (Granit, 1947; Kuffler et al., 1957), differences in the underlying mechanisms have not been described. Here, maintained activity is defined as ongoing spiking in the absence of modulated light, and spontaneous activity refers to spiking that is generated intrinsically (i.e., independent of synaptic input).

In whole-cell recordings in the isolated intact mouse retina, we found maintained activity in ON and OFF RGCs (both OFF $\mathrm{T}$ and OFF S) under dark- and lightadapted conditions, consistent with previous experiments in several species both in vivo (Barlow and Levick, 1969; Sagdullaev and McCall, 2005) and in vitro (O’Brien et al., 2002; Zaghloul et al., 2003). There was considerable variability in mean rate among cells of the same type, especially in the dark, also consistent with previous work (Rodieck and Smith, 1966; Rodieck, 1967). Because the experiments that follow were done in the presence of synaptic antagonists rendering the retina insensitive to light, the dark adaptational state of the retina was not maintained, and recordings were performed under light-adapted conditions (see Materials and Methods).

Effects of L-APB on maintained activity To evaluate the role of synaptic input in the generation of maintained activity, we

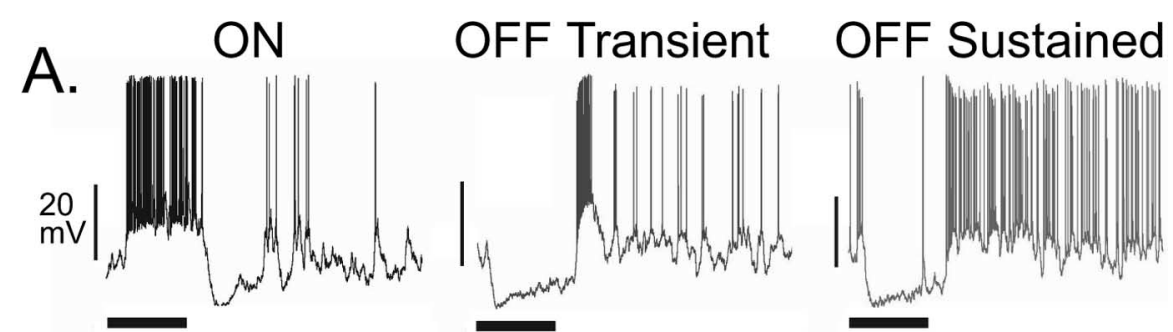

B Light on, $0.5 \mathrm{~s}$
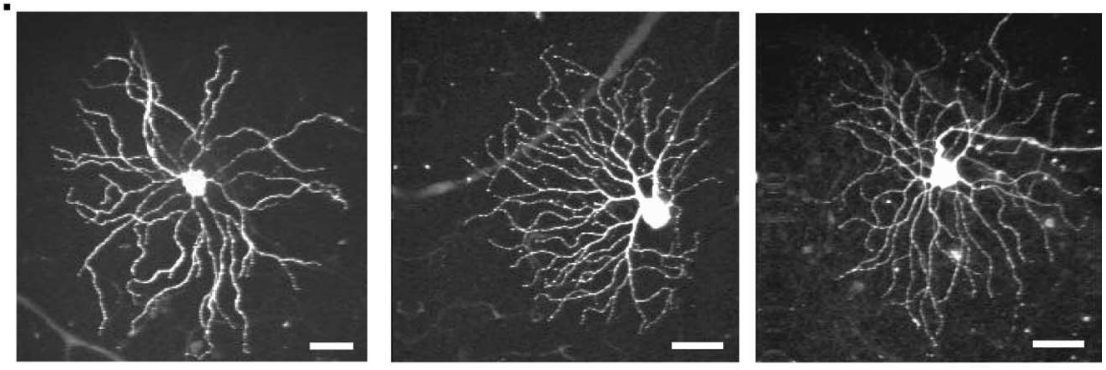

C.

Green channel
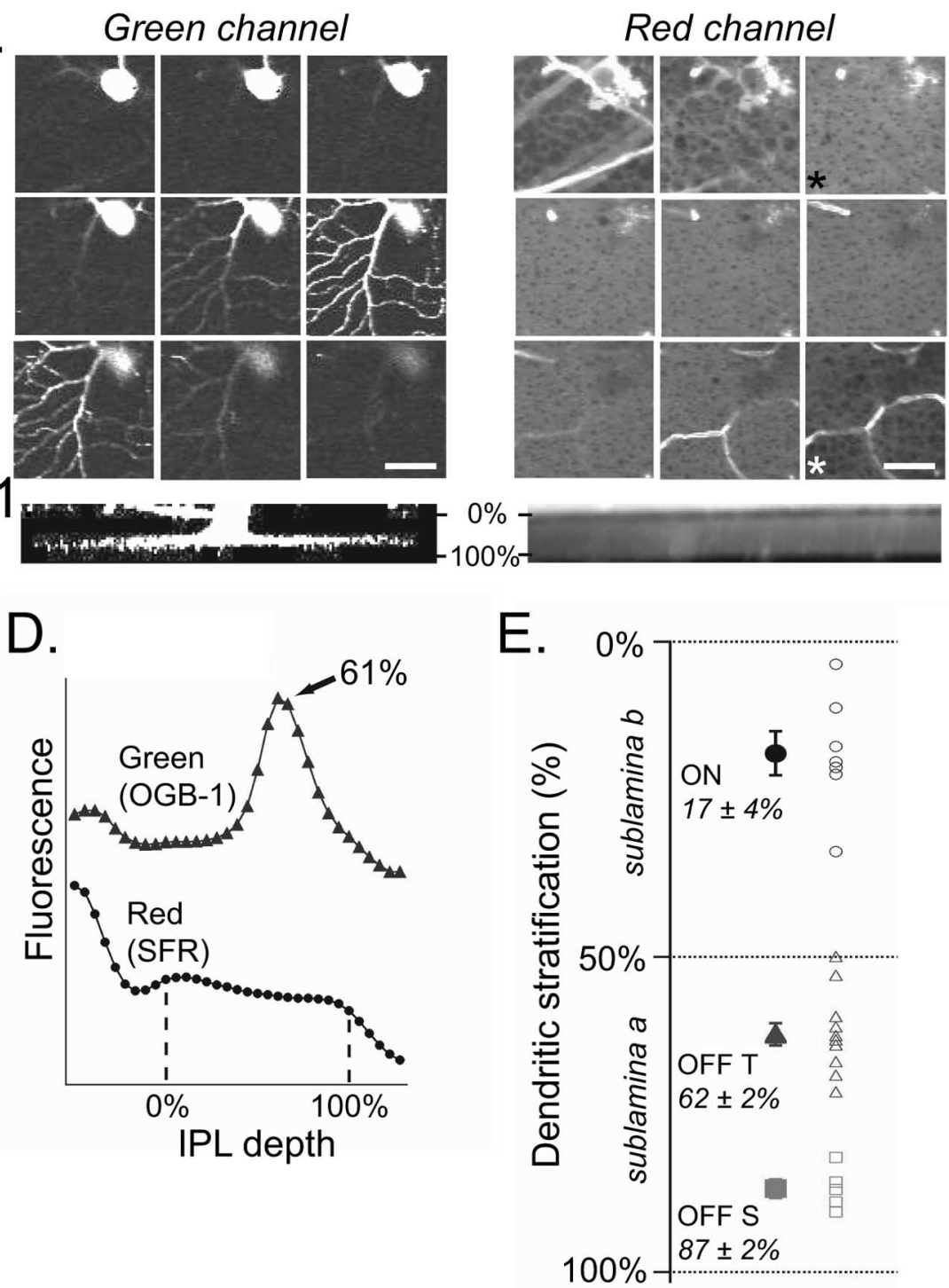

Figure 1. Identification of retinal ganglion cell types. $A$, Light responses of ON, OFF T, and OFF SRGCS. Responses are whole-cell current-clamp recordings from cells to a $0.5 \mathrm{~s}$ step of light (bar light monitor). $\boldsymbol{B}$, Two-photon fluorescence images of representative ON, OFF T, and OFF S RGCs filled with $140 \mu \mathrm{M}$ OGB-1. Each image is a Z-projection acquired in functionally intact retina after removing the recording pipette. $C$, Left, Individual Z-series images from the green channel showing OGB-1 fluorescence and the dendritic structure of the OFF T cell in $\boldsymbol{B}$. Right, Corresponding images from the red channel acquired simultaneously 

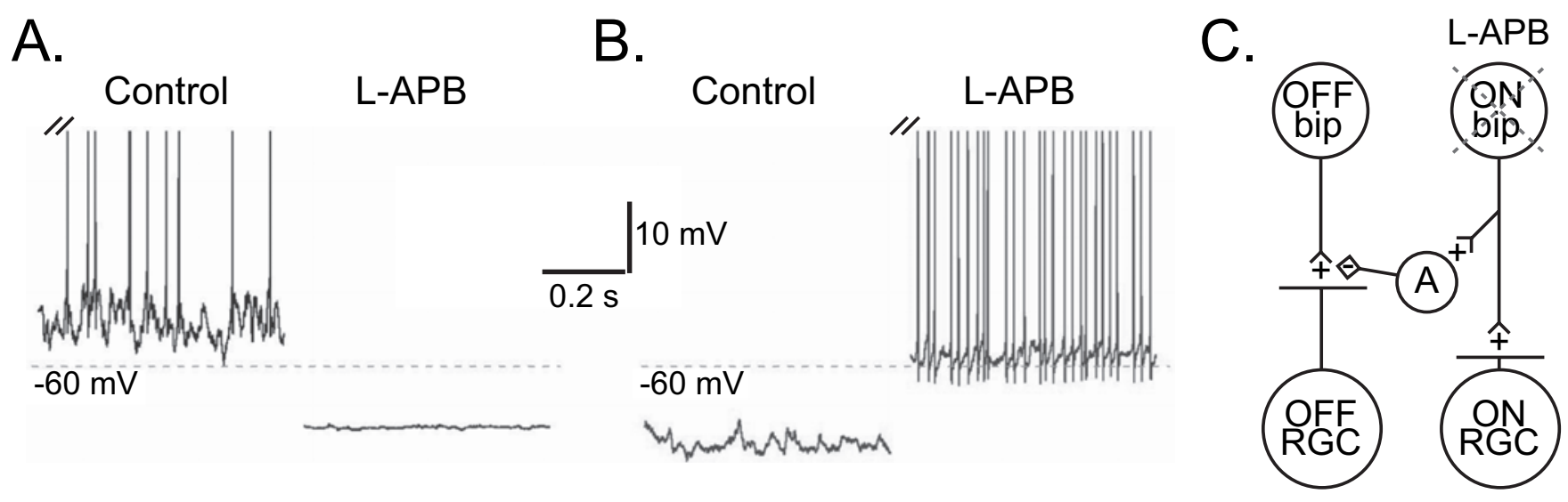

Figure 2. Differential effect of $\mathrm{L}-\mathrm{APB}$ on maintained firing of $\mathrm{ON}$ and $\mathrm{OFF} \mathrm{RGCS} . \boldsymbol{A}$, Whole-cell current-clamp recordings from an example ON RGC in light-adapted retina in control conditions (left) and in the presence of $50 \mu \mathrm{m} \mathrm{L-APB} \mathrm{(right).} \mathrm{L-APB} \mathrm{abolished} \mathrm{spiking} \mathrm{and} \mathrm{underlying} \mathrm{voltage} \mathrm{fluctuations} \mathrm{and} \mathrm{caused} \mathrm{an} \sim 10 \mathrm{mV}$ hyperpolarization. $\boldsymbol{B}$, Whole-cell current-clamp recording from an example OFF T cell in control conditions (left) and after the application of L-APB (right). Note that, in the OFF T cell, in contrast to the ON cell, L-APB caused $\sim 8 \mathrm{mV}$ depolarization and an increase in firing rate. C, Schematic of synaptic circuitry proposed to underlie differential effect of L-APB on ON and OFF pathways (Wässle et al., 1986; Zaghloul et al., 2003). L-APB blocks the ON pathway, decreasing amacrine cell-mediated inhibition of OFF bipolar (bip) and ganglion cells, resulting in disinhibition of OFF RGCS.

first blocked the ON pathway using L-APB (Slaughter and Miller, 1981; Bolz et al., 1984; Schiller et al., 1986). Bath application of 50 $\mu \mathrm{M}$ L-APB hyperpolarized ON RGCs and abolished their maintained firing (Fig. $2 A$ ). These results are consistent with previous experiments in rabbit, cat, and guinea pig and indicate that the origin of maintained firing in ON cells arises from tonic synaptic drive from ON bipolar cells (Massey et al., 1983; Bolz et al., 1984; Zaghloul et al., 2003). L-APB had the opposite effects on the maintained firing of OFF cells, causing a $\sim 10 \mathrm{mV}$ depolarization and an increase in spike rate (Fig. $2 B$ ). Similar effects were seen in OFF S RGCs (data not shown). The differential effect of L-APB on ON and OFF RGC firing has been reported previously in other species (Massey et al., 1983; Bolz et al., 1984; Wassle et al., 1986; Zaghloul et al., 2003) and has been interpreted as showing that the ON pathway provides tonic inhibition to the OFF pathway, most likely through an inhibitory amacrine interneuron (Fig. $2 C)$. Implicit in this explanation is the assumption that disinhibition of the OFF pathway leads to increased synaptic excitation of OFF RGCs from OFF bipolar cells. Blocking ionotropic glutamatergic transmission, which has not been done in previous experiments, can test this interpretation. If disinhibition is the source of increased excitation of OFF RGCs, the addition of glutamate antagonists would be expected to eliminate the activity of OFF RGCs. Alternatively, if OFF cells are spontaneously active, their activity would continue in the presence of antagonists that blocked synaptic input.

\section{Activity in the presence of synaptic blockers}

To test whether maintained activity of OFF RGCs depends on synaptic input, we applied a mixture of synaptic blockers that contained, in addition to L-APB, CNQX, APV, strychnine, and picrotoxin (for concentrations, see Materials and Methods) to block AMPA, NMDA, glycine, and GABA receptors, respectively.
Figure $3 A$ shows the effects of this blocker mixture on the maintained activity of ON, OFF T, and OFF S RGCs. As in L-APB alone, ON cells hyperpolarized and stopped spiking, and membrane voltage fluctuations were reduced (Fig. 3A1). In contrast, both OFF $\mathrm{T}$ and OFF S RGCs depolarized and spiking became highly regular (Fig. $3 A 2, A 3$ ). Figure $3 B$ illustrates the effects of blockers on $V_{\text {rest }}$ and mean firing rate for the cells in Figure $3 A$. In addition, blockers caused a narrowing of ISI distributions and a decrease in the coefficient of variation $(\mathrm{CV}=\mathrm{SD} / \mathrm{mean})$ of all ISIs in the distribution (Fig. $3 C$ ), which indicates an increase in the regularity of firing. A subset of experiments showed that these results were unaffected by using a fortified mixture that also included either $50 \mu \mathrm{M}$ CGP 55845 to block $\mathrm{GABA}_{\mathrm{B}}$ receptors or $50 \mu \mathrm{M}$ curare and $100 \mu \mathrm{M}$ carbenoxelone to block nicotinic acetylcholine receptors and gap junctions, respectively.

The differential effects of synaptic blockers on ON and OFF RGCs are summarized in Figure 3D and Table 1. These experiments demonstrate that synaptic input is not required for maintained activity in OFF RGCs and indicate that OFF cells are capable of intrinsically generated spontaneous activity.

\section{Differences in intrinsic properties revealed by modulation of spontaneous activity}

Burst firing and subthreshold oscillations

Spontaneously active neurons express a combination of voltagegated ion channels that underlie their activity. Consequently, these cells often display other membrane properties such as burst firing and subthreshold voltage oscillations (Llinas, 1988). Because OFF RGCs generate spontaneous activity and ON RGCs do not, we considered whether these cell types could be distinguished on the basis of differences in these features of their electrical behavior.

\section{$\leftarrow$}

showing fluorescence of bath-applied sulforhodamine-101 (SFR). Asterisks represent the images associated with the borders of the IPL. The figure shows 9 of 33 images of this stack (1.6 $\mu \mathrm{m}$ Z-step size). C1, Left, Side projection of image sequence from $\boldsymbol{C}$ showing planar structure of dendritic tree. Right, Side projection from C showing sulforhodamine-101 staining acquired simultaneously. IPL borders are drawn from 0\% (proximal) to 100\% (distal). D, Measurement of dendritic stratification in 0FF T cell. Peak location was measured as 61\%. $\boldsymbol{E}$, Mean dendritic stratification levels for $0 \mathrm{~N}(n=7), 0 \mathrm{FFT}(n=12)$, and OFFS $(n=5)$ cells, measured using methods illustrated in $\boldsymbol{C}$ and $\boldsymbol{D}$. Filled symbols are means, and open symbols are measurements from individual cells. Group means \pm SEM are indicated; all groups significantly different, $p<0.01$. Scale bars: $\boldsymbol{B}, 50 \mu \mathrm{m} ; \boldsymbol{C}, 25 \mu \mathrm{m}$.
To investigate this, spontaneous firing in OFF RGCs was disrupted using steps of negative current applied through the somatic patch electrode (Fig. 4). For a direct comparison between ON and OFF RGCs, we first depolarized ON cells with positive current to bring their membrane potential and spike rate close to that of spontaneously active OFF cells (Fig. 4A1). In ON, 
OFF T, and OFF S cells, spiking could be modulated with negative current. In OFF $\mathrm{T}$ cells, steps to voltages just below spike threshold revealed subthreshold oscillations in the interspike membrane potential (Fig. 4A2, inset). Some (2 of 10) of these cells also fired bursts at intermediate levels of hyperpolarization (data not shown), although bursting was weaker in OFF T than OFF S cells. In (6 of 12) OFF S cells, regular spiking changed to fullblown bursts before being silenced (Fig. $4 A 3$, inset). ON cells showed no evidence of bursting (Fig. 4A1; 0 of 8 cells). We observed similar bursting behavior in OFF RGCs by applying positive current steps after first silencing spontaneous activity with negative current (data not shown).

To measure bursting, the CV of ISIs during responses to negative current steps was plotted as a function of mean $V_{\mathrm{m}}$ during the step (Fig. 4B). Each point on the plot represents a measurement from a single spike train at a given mean membrane potential, and responses from several cells are pooled. $\mathrm{CV}$ is a common measure of the regularity of spiking, in which high values reflect high variability and low values reflect low variability or high regularity (Tolhurst et al., 1981; Frishman and Levine, 1983; Shadlen and Newsome, 1998). These measures revealed two important points. First, OFF cells showed a higher occurrence of burst firing than $\mathrm{ON}$ cells, as reflected by larger $C V$ values. Second, when hyperpolarized, OFF cells had a lower threshold for spiking than ON cells. These experiments indicate that OFF RGCs have a greater intrinsic capacity for burst firing than ON RGCs.

\section{Subthreshold oscillations}

To obtain more detailed measurements of subthreshold oscillations, we performed additional experiments using negative current steps to disrupt spontaneous spike activity. Figure $5 \mathrm{~A}$ shows example responses of each cell type to hyperpolarizing steps that suppress spontaneous activity. As in Figure 4, positive current was injected into ON cells to approximately match OFF cell firing rate and mean $V_{\mathrm{m}}$. In the ON cell (Fig. $5 A 1$ ), a $-40 \mathrm{pA}$ current step revealed small $(\sim 2-3 \mathrm{mV})$ fluctuations in $V_{\mathrm{m}}$ that became more pronounced in the region just before the cell began to spike. With a larger current step that silenced the firing, $V_{\mathrm{m}}$ fluctuations were essentially abolished. In the OFF T cell (Fig. 5A2), a small negative current step revealed prominent $(3-4 \mathrm{mV})$, sharp fluctuations in $V_{\mathrm{m}}$. With a larger current step, these fluctuations became smaller but increased later in the sweep as the voltage relaxed to a more positive potential. Similar results were observed in OFF S cells (Fig. 5A3), but the voltage fluctuations in these cells were typically slower and less sharp.

Figure $5 B$ shows summary data quantifying subthreshold oscillations from ON, OFF T, and OFF S RGCs. Each plot shows the CV of $V_{\mathrm{m}}$ versus mean $V_{\mathrm{m}}$, in which each point represents a measurement taken from one subthreshold sweep when no

Group data

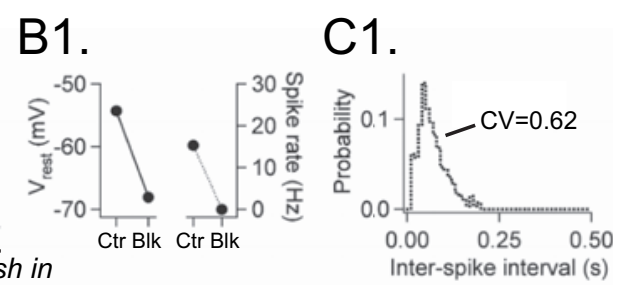

B2.

C2.
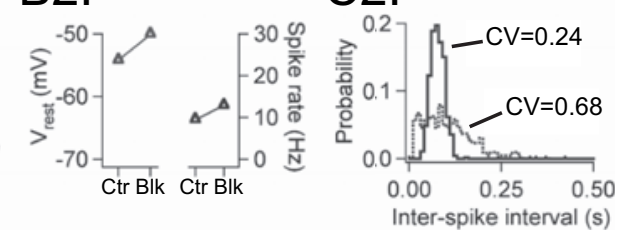

B3.

C3.
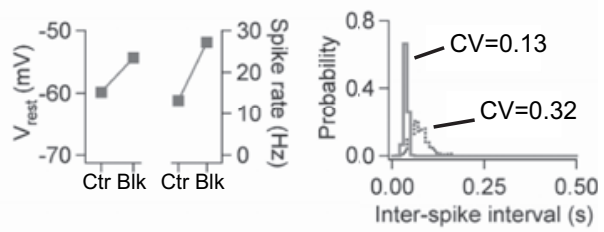

Figure 3. Maintained firing of OFF RGCs persists in synaptic blockers. $A$, Whole-cell current-clamp recordings showing the effect of synaptic blocker mixture on maintained firing of ON (A1), OFF T (A2), and OFFS (A3) RGCs in light-adapted retina. Vertical (B) (D4) in the absence and presence of blocker mixture (mean \pm SEM) (for values, see Table 1). The blockers mixture contained (in $\mu \mathrm{M}) 50 \mathrm{~L}-\mathrm{APB}, 20 \mathrm{CNQX}, 50 \mathrm{APV}, 1$ strychnine, and 50 picrotoxin in this and all subsequent figures unless noted otherwise.

spikes were present (see Materials and Methods). Analysis of a group of ON cells (Fig. 5B1) revealed a voltage dependence of subthreshold oscillations, in which oscillation strength increased with increasing $V_{\mathrm{m}}$. This voltage dependence was striking for OFF T cells (Fig. 5B2) but less pronounced for OFF S cells (Fig. $5 B 3$ ). Averaged across all voltages, the mean oscillation strength for OFF cells was larger than for ON cells, reflecting largeramplitude subthreshold oscillations in OFF than ON RGCs.

\section{Rebound firing}

Intrinsic properties such as burst firing and subthreshold oscillations are often associated with postinhibitory rebound firing, i.e., a burst of spikes after a hyperpolarizing stimulus (Llinas and Yarom, 1981; Jahnsen and Llinas, 1984). Consistent with this combination of properties, we found that OFF, but not ON, RGCs fired rebound bursts after negative current steps. This is illustrated in Figure 6, which compares the responses to the termination of negative current steps in the three cell types. Before delivering current steps, negative holding current was applied to OFF cells that silenced their spontaneous activity and brought their resting potentials to values similar to that of $\mathrm{ON}$ cells. These results indicate that OFF, but not ON, RGCs have the ability to generate rebound burst firing. This is an important topic (Guen- 
Table 1. Effects of synaptic blockers on physiological properties of ON, OFF T, and OFF S RGCS

\begin{tabular}{|c|c|c|c|c|c|c|c|c|}
\hline & $\begin{array}{l}V_{m} c t r l \\
(\mathrm{mV})\end{array}$ & $\begin{array}{l}V_{\mathrm{m}} \text { block } \\
(\mathrm{mV})\end{array}$ & $\begin{array}{l}R_{\mathrm{n}} \mathrm{ctrl} \\
(\mathrm{M} \Omega)\end{array}$ & $\begin{array}{l}R_{\mathrm{n}} \text { block } \\
(\mathrm{M} \Omega)\end{array}$ & $\begin{array}{l}\text { Rate ctrl } \\
(\mathrm{Hz})\end{array}$ & $\begin{array}{l}\text { Rate block } \\
(\mathrm{Hz})\end{array}$ & $\begin{array}{l}\text { CV ctrl } \\
\text { (SD/mean) }\end{array}$ & $\begin{array}{l}\text { CV block } \\
\text { (SD/mean) }\end{array}$ \\
\hline ON & $-54.8 \pm 2.7$ & $-65.5 \pm 1.3$ & $57.6 \pm 2.6$ & $57.3 \pm 6.3$ & $14.0 \pm 3.5$ & & $0.61 \pm 0.05$ & \\
\hline OFF T & $-60.3 \pm 2.7$ & $-54.6 \pm 1.0$ & $58.6 \pm 7.3$ & $67.5 \pm 6.6$ & $14.3 \pm 5.5$ & $20.3 \pm 3.0$ & $0.54 \pm 0.10$ & $0.27 \pm 0.03$ \\
\hline OFFS & $-60.2 \pm 2.1$ & $-55.1 \pm 1.1$ & $60.5 \pm 6.7$ & $117.1 \pm 15.9$ & $16.6 \pm 5.4$ & $43.3 \pm 3.5$ & $0.33 \pm 0.04$ & $0.14 \pm 0.01$ \\
\hline$n$ & $6,7,4$ & $9,7,11$ & $5,7,6$ & $5,6,9$ & $9,7,5$ & $9,8,10$ & $9,5,5$ & $9,8,10$ \\
\hline \multicolumn{9}{|l|}{$t$ test } \\
\hline ON-OFF T & NS & $* *$ & NS & NS & NS & & NS & \\
\hline ON-OFFS & NS & $* *$ & NS & * & NS & & $* *$ & \\
\hline OFF T-OFFS & NS & NS & NS & * & NS & ** & NS & $* *$ \\
\hline
\end{tabular}

Shown are changes in measured $V_{m}$, input resistance $\left(\mathrm{R}_{\mathrm{n}}\right)$, mean firing rate, and $\mathrm{C}$ of interspike intervals for each cell type. ctrl, Control. ${ }^{*} p<0.05,{ }^{* *} p<0.01 ; \mathrm{NS}, p \geq 0.05$. Data are mean \pm SEM. For explanation of measurements, see Materials and Methods.
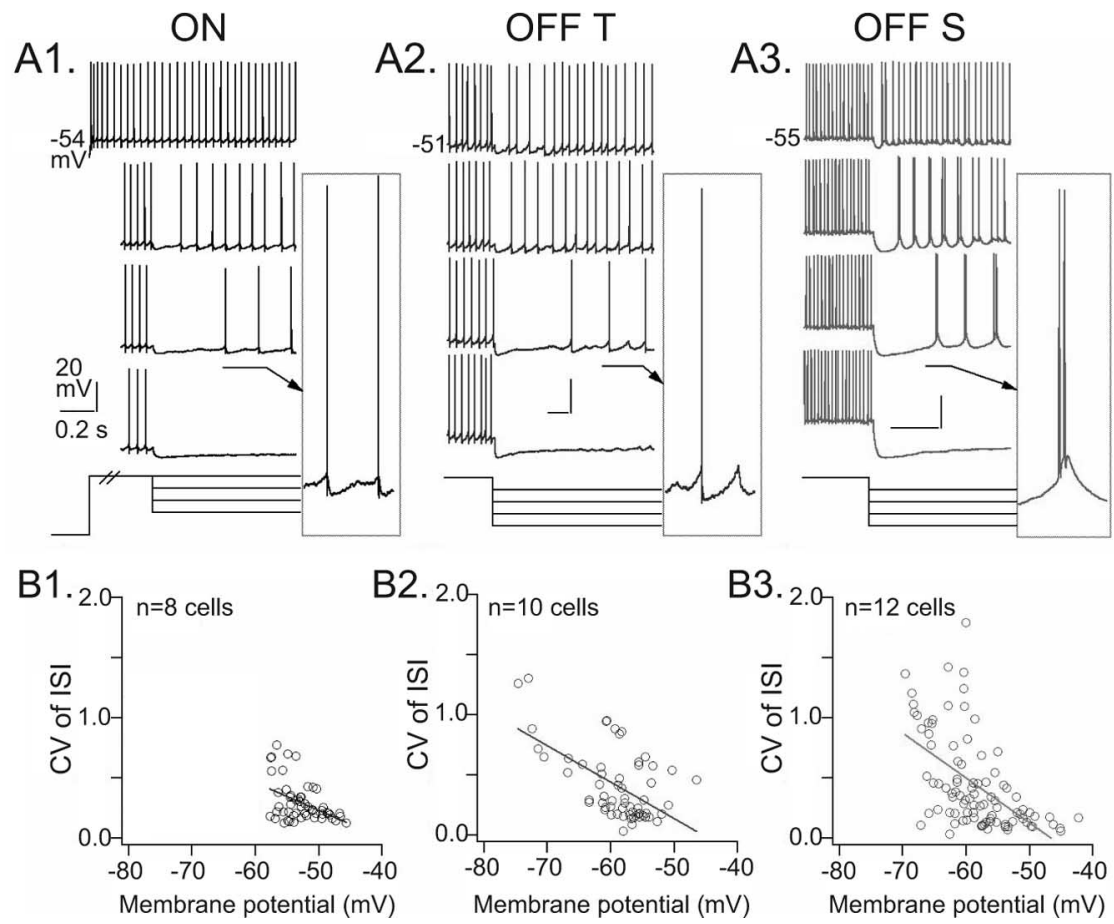

Figure 4. Disruption of spontaneous activity reveals bursts in OFF RG(S. A, Responses to hyperpolarizing current steps applied through the somatic patch electrode in ON (A1), OFF T (A2), and OFFS (A3) RGCs. Current steps are superimposed and shown below voltage recordings. For comparison, $0 \mathrm{~N}$ cells were first depolarized so $V_{m}$ and firing rate matched that of $0 \mathrm{FF}$ cells. Insets show portions of sweeps on expanded timescale, as indicated. Note the presence of high-frequency bursts in $A 3$. B, CV of ISI for pooled responses plotted as a function of $V_{\mathrm{m}}$ for $\mathrm{ON}(\boldsymbol{B} 1), 0 \mathrm{FF} T(\boldsymbol{B} 2)$, and $0 \mathrm{FFS}(\boldsymbol{B} 3)$. Mean $C V$ values across all voltages were $0.29 \pm 0.02$ for $0 \mathrm{~N}$ cells, $0.40 \pm 0.04$ for $0 \mathrm{FF} \mathrm{T}$ cells, and $0.43 \pm 0.04$ for OFF S cells ( $p=0.010,0.008$ for $0 \mathrm{~N}$ compared with OFF T and OFFS; $p=0.59$ for $0 \mathrm{FF}$ T compared with OFF S). Experiments were done in the presence of synaptic blocker mixture.

ther et al., 1994; Lee et al., 2003) and will be examined more thoroughly in future work.

In summary, disrupting the spontaneous activity of OFF RGCs with negative current injection revealed burst firing from negative potentials, subthreshold voltage oscillations, and rebound burst firing. ON RGCs, in contrast, did not fire bursts, showed smaller-amplitude subthreshold oscillations, and were not capable of rebound firing. Because these experiments were performed in the presence of a mixture of synaptic blockers, they demonstrate that the membrane properties ON and OFF RGCs are intrinsically different.

\section{Generation of spontaneous activity}

The steady depolarization that drives spontaneous (pacemaker) activity arises through different mechanisms in different types of neurons (Harris-Warrick, 2002). To investigate the origin of spontaneous activity in OFF RGCs, we consid- ered mechanisms that were dependent on either calcium or sodium currents.

\section{Mechanism 1: calcium}

Because $\mathrm{Ca}^{2+}$ plays an important role in generating spontaneous activity in pacemaker cells from the heart (Kass and Tsien, 1982) and CNS (Llinas and Sugimori, 1980), $\mathrm{Ca}^{2+}$ channel blockers were used to evaluate the dependence of spontaneous firing in OFF RGCs on voltagegated $\mathrm{Ca}^{2+}$ channels. The effects of $\mathrm{Ni}^{2+}$ were tested first because OFF RGCs express a low-threshold, transient inward current in the presence of TTX that is blocked by $100 \mu \mathrm{M} \mathrm{Ni}{ }^{2+}$ (Fig. 7A). The results of a separate series of experiments (our unpublished observations) show that this current is mostly inactivated at rest, has a low-voltage activation threshold, and is associated with increases in intracellular $\mathrm{Ca}^{2+}$, all characteristic features of T-type $\mathrm{Ca}^{2+}$ channels.

The effects of $100 \mu \mathrm{M} \mathrm{Ni}^{2+}$ on spontaneous activity in an example OFF T cell are shown in Figure $7 B$. In the presence of the synaptic blocker mixture, firing was regular, with a baseline $V_{\mathrm{m}}$ of $-54 \mathrm{mV}$ (Fig. 7B1). After addition of $100 \mu \mathrm{M} \mathrm{Ni}{ }^{2+}$, mean spike rate decreased, but baseline $V_{\mathrm{m}}$ depolarized to $-51 \mathrm{mV}$ (Fig. 7B2). In six OFF T cells, $\mathrm{Ni}^{2+}$ caused a small but significant depolarization (Fig. 7B3) $(p<$ 0.01 , paired $t$ test). If $\mathrm{T}$-type $\mathrm{Ca}^{2+}$ current provides a depolarizing drive important for the generation of spontaneous activity, $\mathrm{Ni}^{2+}$ application should cause the cell to hyperpolarize rather than depolarize as observed. This result suggests that $\mathrm{Ni}^{2+}$ sensitive low-threshold $\mathrm{Ca}^{2+}$ channels do not provide the depolarizing drive underlying spontaneous activity in OFF cells.

The effect of $\mathrm{Ni}^{2+}$ on subthreshold oscillations was also investigated (Fig. 7C). In the presence of synaptic blockers, a series of hyperpolarizing current steps in a different OFF $\mathrm{T}$ cell resulted in prominent voltage-dependent subthreshold oscillations (Fig. 7C1) that continued in the presence of $100 \mu \mathrm{M} \mathrm{Ni}^{2+}$ (Fig. 7C2), with no significant change in oscillation strength $(p=0.33$, paired $t$ test; $n=3$ ) (Fig. 7B3).

To assess the role of other $\mathrm{Ca}^{2+}$ channel types in generating spontaneous activity in OFF RGCs, we measured the effects of the L-type $\mathrm{Ca}^{2+}$ channel blockers nimodipine and nifedipine and the 
wide-spectrum $\mathrm{Ca}^{2+}$ channel blocker $\mathrm{Cd}^{2+}$. Spontaneous activity persisted in the presence of $20 \mu \mathrm{M}$ nifedipine, $20 \mu \mathrm{M}$ nimodipine, or $300 \mu \mathrm{M} \mathrm{Cd}{ }^{2+}$ (data not shown). Changes in firing properties were apparent in the presence of these compounds, especially $\mathrm{Cd}^{2+}$, which caused increased burst firing, but this was difficult to interpret given the wide range of secondary effects associated with $\mathrm{Cd}^{2+}$ application [e.g., effects on $\mathrm{Ca}^{2+}$-activated $\mathrm{K}^{+}$ channels, which leads to bursting in other types of neurons (Traub et al., 2003)]. However, the persistence of spontaneous activity was clear in the presence of $\mathrm{Ni}^{2+}$, nifedipine, nimodipine, and $\mathrm{Cd}^{2+}$.

These data indicate that spontaneous firing does not require voltage-gated $\mathrm{Ca}^{2+}$ channels, and we conclude that, although present in OFF RGCs, they do not provide the primary depolarizing drive underlying spontaneous activity. This does not, however, exclude the possibility that $\mathrm{Ca}^{2+}$ plays a modulatory role.

\section{Mechanism 2: sodium}

Persistent $\mathrm{Na}^{+}$entry through voltagegated $\mathrm{Na}^{+}$channels is responsible for pacemaker activity in several types of central neurons (Pennartz et al., 1997; Taddese and Bean, 2002; Do and Bean, 2003). Although immunocytochemistry studies have shown that mammalian RGCs express $\mathrm{Na}^{+}$channels subtypes that can mediate persistent $\mathrm{Na}^{+}$current $\left(I_{\mathrm{NaP}}\right.$ ), e.g., $\mathrm{Na}_{\mathrm{V}} 1.6$ (Van Wart and Matthews, 2006b), the presence of such a current has only been demonstrated electrophysiologically in goldfish ganglion cells (Hidaka and Ishida, 1998). Thus, we asked, first, do mouse RGCs have $I_{\mathrm{NaP}}$, and, second, does it play a role in generating spontaneous activity?

\section{Evidence for persistent $\mathrm{Na}^{+}$current in ON and OFF RGCs}

To test for $I_{\mathrm{NaP}}$ in ON and OFF RGCs, we applied slow voltage ramps ( -90 to $-10 \mathrm{mV}$ at $16 \mathrm{mV} / \mathrm{s}$ ) in whole-cell voltage clamp (Fig. 8A), following standard protocols for measuring this current (Stafstrom et al., 1985; Crill, 1996; Pennartz et al., 1997; Powers and Binder, 2003). The measurement of $I_{\mathrm{NaP}}$ in an OFF S cell is illustrated in Figure $8 \mathrm{~B}$. Subtraction of the ramp current recorded in the presence and absence of TTX isolated a TTXsensitive $I_{\mathrm{NaP}}$ that activated (defined as $5 \%$ maximum) at -65 $\mathrm{mV}$ and had a peak amplitude of $-180 \mathrm{pA}$ (Fig. $8 \mathrm{C}$ ). There were no significant differences in the average peak amplitude and activation voltage in ON, OFF T, and OFF S RGCs (Table 2).

To determine whether the $V_{\text {rest }}$ is within the activation range of the persistent current, steady-state voltage was measured in whole-cell current-clamp recordings in the presence of synaptic blockers and TTX. Figure $8 E$ shows mean $V_{\text {rest }}$ plotted against mean $I_{\mathrm{NaP}}$ activation voltage $\left(V_{\text {activ }}\right.$ ) for the three cell types. For ON cells, $V_{\text {activ }}$ was not different from $V_{\text {rest }}$, indicating that $I_{\mathrm{NaP}}$ is on average $\leq 5 \%$ active at rest. For OFF T and OFF $S$ cells, $V_{\text {activ }}$ was negative to $V_{\text {rest }}$, indicating that $I_{\mathrm{NaP}}$ is active at rest in these cells (for statistical tests, see Table 2).

These results show that ON, OFF T, and OFF S RGCs express $I_{\mathrm{NaP}}$ with similar voltage activation range and peak amplitude. However, $V_{\text {rest }}$ for OFF T and OFF S cells is significantly more positive to $V_{\text {activ }}$, placing their resting voltages well into the activation range. This suggests that $I_{\mathrm{NaP}}$ in OFF, but not ON, RGCs may contribute a steady depolarizing drive at $V_{\text {rest }}$.

\section{Effect of TTX on spontaneous activity and subthreshold oscillations}

To test the proposal that $I_{\mathrm{NaP}}$ contributes to the generation of spontaneous activity in OFF RGCs, we measured the effects of TTX on spontaneous firing and subthreshold oscillations. Figure $9 A$ shows whole-cell current-clamp recordings of spontaneous firing during wash in of $0.1 \mu \mathrm{M}$ TTX for example cells of each type. ON cells were first depolarized with positive current to match OFF cell $V_{\mathrm{m}}$ and firing rate; TTX had no effect on $V_{\mathrm{m}}$ in ON cells without first being depolarized, consistent with the result that $V_{\text {rest }}$ in ON cells is negative to the activation range of $I_{\mathrm{NaP}}$ (Fig. 8). During wash in, fast spikes were abolished first, revealing fluctuations in membrane voltage. Insets show voltage fluctuations on an expanded timescale. Note that fluctuations were sharp and fast for OFF T cells, slower and larger for OFF S cells, and smaller in ON cells compared with both types of OFF cells. As wash in continued, voltage fluctuations were also abolished, and cells hyperpolarized by $\sim 3-5 \mathrm{mV}$. These results suggest that subthreshold oscillations are TTX sensitive.

To test this more directly, we compared the strength of subthreshold oscillations before and after TTX application. As in Figure 4, spontaneous spiking in OFF cells was silenced by injecting hyperpolarizing current. Figure $9 B$ shows the effect of TTX on subthreshold oscillations from an example OFF T cell. Suppression of spontaneous activity revealed prominent subthreshold oscillations (Fig. 9B1) that were abolished by $0.1 \mu \mathrm{M}$ TTX (Fig. 9B2). Oscillation strength versus $V_{\mathrm{m}}$ is illustrated for a collection of OFF $\mathrm{T}$ cells in Figure $9 C$, showing that TTX reduced the strength of oscillations and their voltage dependence. Although this was true for all three cell types (Fig. 9D), the TTX-sensitive oscillations were twofold to threefold larger in OFF cells compared with ON cells (Table 2). 


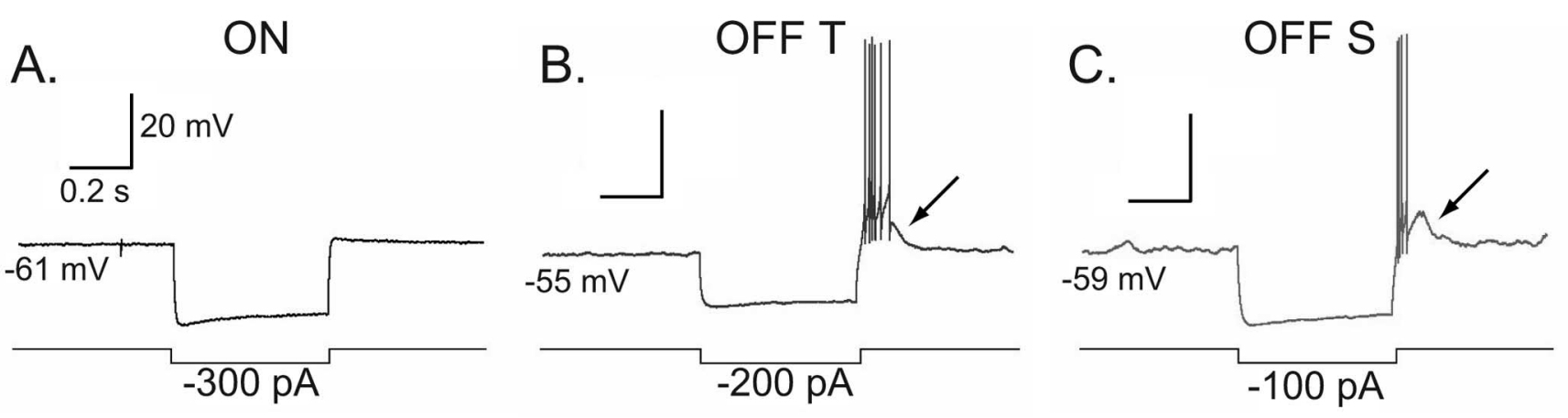

Figure 6. Postinhibitory rebound firing in OFF RGCs. Responses to a 0.5 s negative current step in example ON (A), OFF T (B), and OFF S (C) RGCs. Negative current injection led to rebound burst firing in OFF T and OFF $S$ cells (arrows) but not in $\mathrm{ON}$ cells. OFF cells were first hyperpolarized by constant negative current to silence spontaneous activity and match $V_{\mathrm{m}}$ to that of $0 \mathrm{~N}$ cells. Current stimuli indicated below voltage records. Experiments were done in the presence of synaptic blockers mixture.
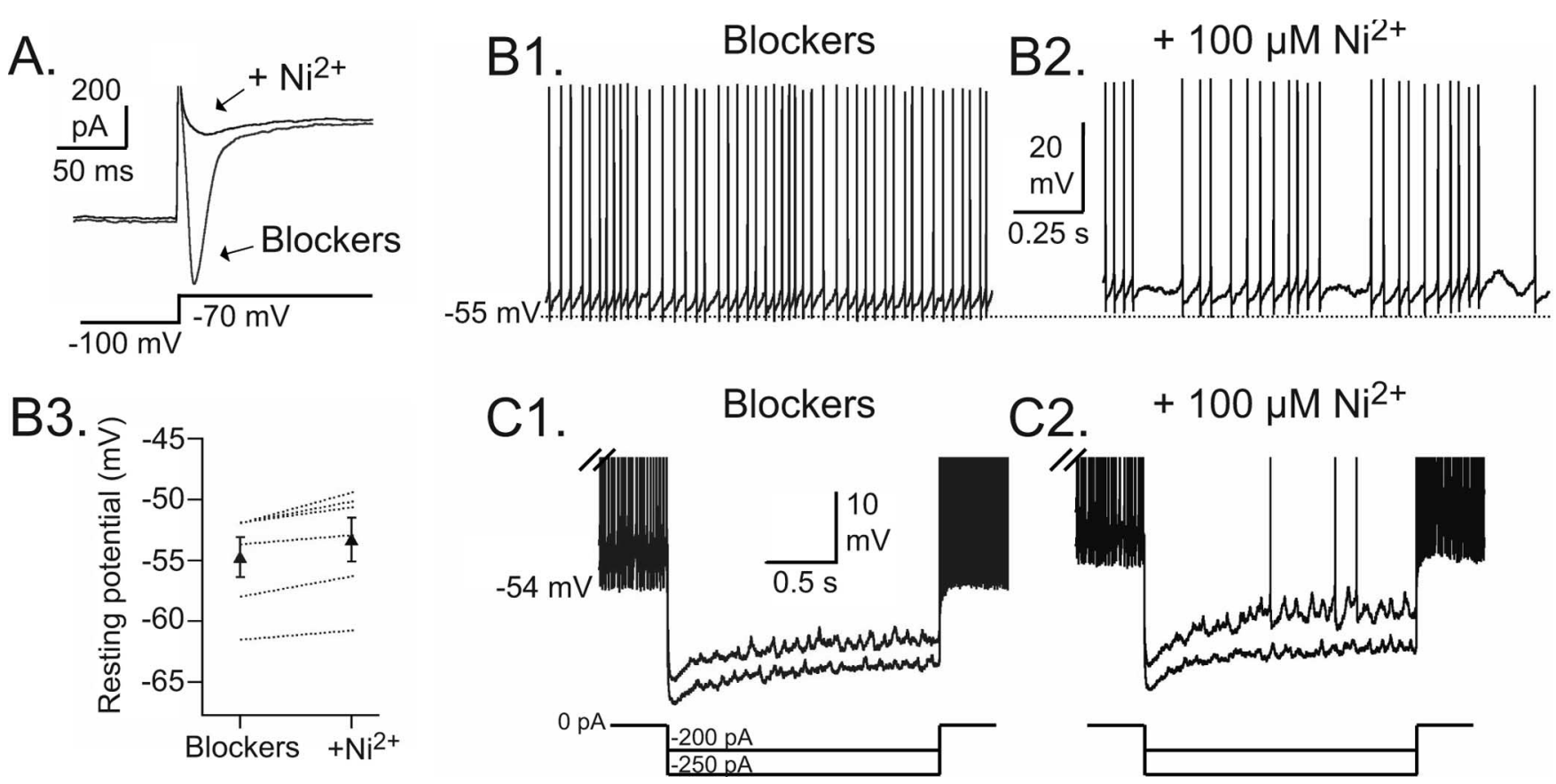

Figure 7. Spontaneous firing in $0 \mathrm{FF} \mathrm{RGCs}$ is not driven by $\mathrm{Ni}^{2+}$-sensitive $\mathrm{Ca}^{2+}$ channels. $A$, Transient $\mathrm{Ni}^{2+}$-sensitive inward current evoked by a voltage step from -100 to $-70 \mathrm{mV}$ (below) in an OFF T cell. Individual responses to the same voltage step are shown before and after application of $100 \mu \mathrm{M} \mathrm{Ni}{ }^{2+}$. Recordings made in voltage-clamp mode in the presence of synaptic blockers and $0.1 \mu \mathrm{M} \mathrm{TTX.} \mathrm{B1,} \mathrm{Spike} \mathrm{activity} \mathrm{recorded} \mathrm{in} \mathrm{whole-cell} \mathrm{current} \mathrm{clamp} \mathrm{from} \mathrm{an} \mathrm{OFF} \mathrm{T} \mathrm{cell} \mathrm{in} \mathrm{the} \mathrm{presence} \mathrm{synaptic} \mathrm{blockers.} \mathrm{B2,} \mathrm{Same} \mathrm{cell} \mathrm{after} \mathrm{addition} \mathrm{of} 100 \mu \mathrm{m} \mathrm{Ni}{ }^{2+}$ to the blocker mixture. Note the $\sim 2-3 \mathrm{mV}$ depolarization and "depolarizing pauses" in firing. B3, Mean change in resting potential in blocker mixture plus $100 \mu \mathrm{m} \mathrm{Ni}^{2+}$ for a group of $0 \mathrm{FFT}$ cells $(+1.5 \pm 0.3 \mathrm{mV} ; n=6 ; p=$ 0.0032, paired $t$ test). C1, Subthreshold oscillations before and after (C2) $\mathrm{Ni}^{2+}$ application. Data from different OFF T cell than shown in $\boldsymbol{B}$.

These results indicate that TTX-sensitive persistent $\mathrm{Na}^{+}$current is active at rest in both OFF T and OFF $S$ cells and suggest that it gives rise to subthreshold oscillations and the generation of spontaneous activity in both of these cell types.

\section{Discussion}

Here we show that a different balance of synaptic and intrinsic mechanisms underlies the generation of maintained activity in $\mathrm{ON}$ and OFF RGCs. The results indicate that ON cells are primarily driven by synaptic input, whereas OFF cells possess active intrinsic properties that drive spontaneous activity in the absence of synaptic input. This represents a major functional difference between ON and OFF retinal circuits at the level of the output cell.

\section{Different intrinsic properties for ON and OFF RGCs}

RGCs have been reported to have differences in firing properties (transient or sustained) (Tabata and Kano, 2002) and in expres- sion of a number of voltage-gated currents (Lipton and Tauck, 1987; Karschin and Lipton, 1989; Kaneda and Kaneko, 1991; Skaliora et al., 1993, 1995; Guenther et al., 1994, 1999; Tabata and Ishida, 1996; Wang et al., 1997, 1998). These studies were done on dissociated cells, however, in which it was not possible to distinguish ON from OFF cell types. There is little information about the electrophysiological properties of identified $\mathrm{ON}$ and OFF cells in the functionally intact retina. Differences in the firing thresholds of these cells in the developing retina have been reported (Myhr et al., 2001), but no systematic studies have been done on intact adult RGCs (but see O’Brien et al., 2002; Zaghloul et al., 2003). Our results demonstrate that intrinsic differences last into adulthood and represent a fundamental feature of mature retina.

\section{Mechanism of spontaneous activity}

TTX abolished subthreshold oscillations and caused hyperpolarization of $V_{\text {rest }}$ in OFF RGCs. This result, along with the presence 

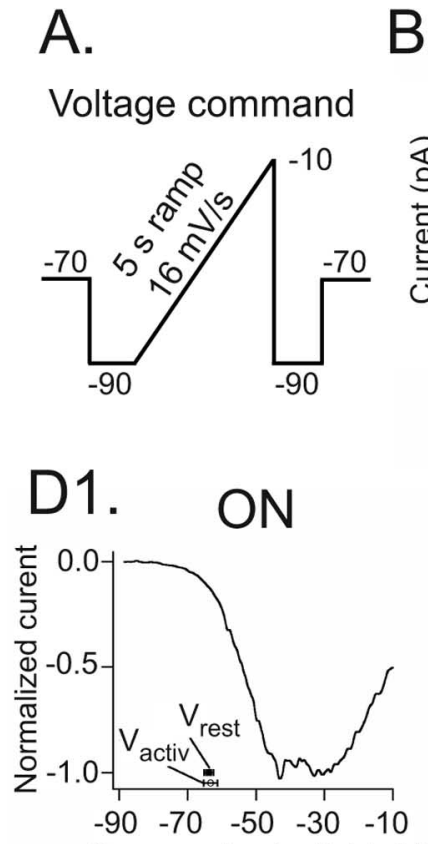

Command potential $(\mathrm{mV})$

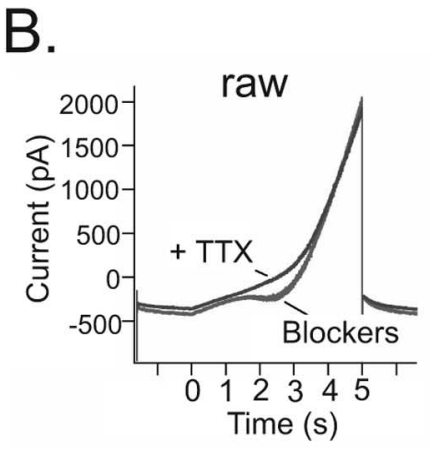

C.
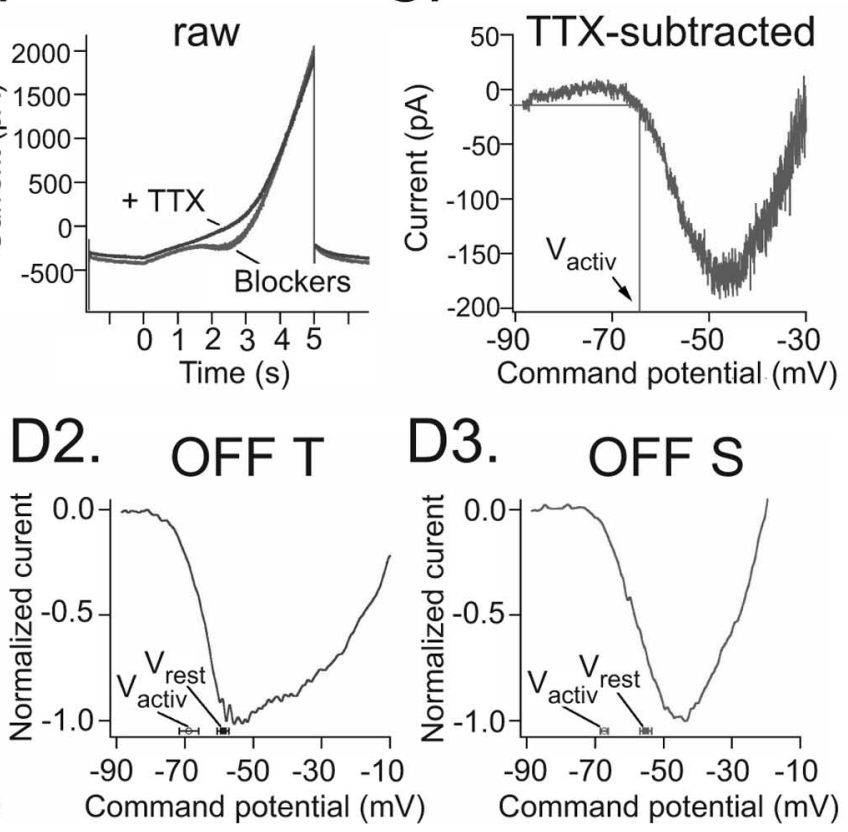

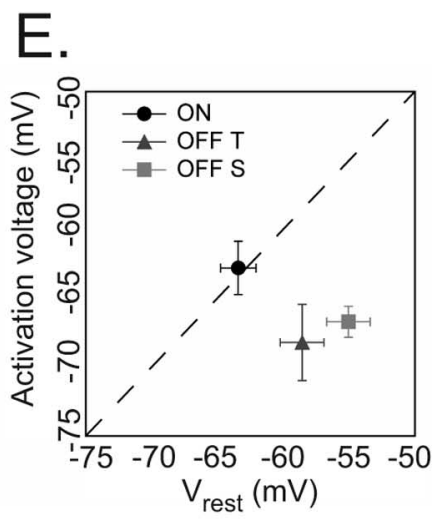

Figure 8. Activation of persistent $\mathrm{Na}^{+}$current $\left(I_{\mathrm{NaP}}\right)$ at rest in OFF RGCs. $\boldsymbol{A}$, Voltage-clamp command used for measuring $I_{\text {Nap. }} \boldsymbol{B}$, Superimposed current traces before and after adding of $0.1 \mu \mathrm{M}$ TTX to the synaptic blocker mixture in response to the voltage command in $A$ for an OFF S RGC. C, Subtraction of "TTX" current from "Blockers" current yields "TTX-subtracted" current. TTX-subtracted current is plotted versus command potential to illustrate its range of voltage activation. $\boldsymbol{D}$, Mean TTX-subtracted currents for $0 \mathrm{~N}(\boldsymbol{D} 1 ; n=6), 0 \mathrm{FF} T(\boldsymbol{D 2} ; n=6)$, and $0 \mathrm{FF} S(\boldsymbol{D 3} ; n=5) \mathrm{RGCs}$. Mean $V_{\text {activ }}$ for TTX-subtracted current and $V_{\text {rest }}$ are indicated on the abscissa for comparison. $E$, Plot of mean $V_{\text {activ }}$ of TTX-sensitive current versus mean $V_{\text {rest }}$ (measured in blocker mixture plus $0.1 \mu m$ TTX). Points above unity indicate resting voltages less than $/_{\text {NaP }}$ activation; points below unity indicate resting voltages greater than $I_{\mathrm{NaP}}$ activation.

Table 2. Properties of TTX-sensitive persistent current $\left(I_{\mathrm{NaP}}\right)$ and subthreshold oscillations

\begin{tabular}{|c|c|c|c|c|c|c|}
\hline & $V_{\text {rest }} \operatorname{TTX}(\mathrm{mV})$ & $I_{\mathrm{NaP}} \operatorname{activ}(\mathrm{mV})$ & $I_{\mathrm{NaP}}$ peak $(\mathrm{pA})$ & $I_{\mathrm{NaP}}$ activ $-V_{\text {rest }}(\mathrm{mV})$ & Sub 0scil blockers $\left(\mathrm{CV} \times 10^{-3}\right)$ & Sub 0scil + TTX $\left(\mathrm{CV} \times 10^{-3}\right)$ \\
\hline ON & $-63.8 \pm 1.4$ & $-63.3 \pm 2.0$ & $-147.6 \pm 27.9$ & 0.5 & $4.2 \pm 0.4$ & $2.7 \pm 0.3$ \\
\hline OFF T & $-58.8 \pm 1.7$ & $-68.8 \pm 2.8$ & $-160.7 \pm 46.2$ & 10.0 & $11.2 \pm 0.7$ & $2.6 \pm 0.1$ \\
\hline OFFS & $-55.2 \pm 1.7$ & $-67.3 \pm 1.2$ & $-206.2 \pm 23.5$ & 12.1 & $8.8 \pm 0.6$ & $4.3 \pm 0.2$ \\
\hline$n$ & $7,5,4$ & $6,6,5$ & $6,6,5$ & $6,5,4$ & $6,7,6$ & $5,4,4$ \\
\hline \multicolumn{7}{|l|}{$t$ test } \\
\hline ON-OFFT & * & NS & NS & NS $(O N)^{\#}$ & $* *$ & NS \\
\hline ON-OFFS & $* *$ & NS & NS & ${ }^{*}(\mathrm{OFF} T)^{\#}$ & $* *$ & ** \\
\hline OFF T-OFF S & NS & NS & NS & ${ }^{* *}(\mathrm{OFFS})^{\#}$ & * & $* *$ \\
\hline
\end{tabular}

Shown are mean resting potential in TTX ( $\left.V_{\text {rest }} \mathrm{TTX}\right)$, activation voltage of measured $I_{\mathrm{NaP}}\left(I_{\mathrm{NaP}}\right.$ activ), peak $I_{\mathrm{NaP}}\left(I_{\mathrm{NaP}}\right.$ peak), difference between $I_{\mathrm{NaP}}$ activ and $V_{\text {rest }}$ subthreshold oscillation strength in blockers (Sub Oscil blockers), and subthreshold oscillation strength in blockers plus TTX (Sub Oscil + TTX). ${ }^{*} p<0.05 ;{ }^{* *} p<0.01 ; \mathrm{NS}, p \geq 0.05$; \#, within-group comparison. Data are mean \pm SEM.

of persistent $\mathrm{Na}^{+}$current in these cells, supports the proposal that spontaneous spike activity is driven by TTX-sensitive $\mathrm{Na}^{+}$ currents that operate at voltages close to spike threshold. Spontaneous activity and subthreshold oscillations in OFF RGCs continue in the presence of external $\mathrm{Ni}^{2+}$, nifedipine, $\mathrm{Cd}^{2+}$, or $\mathrm{Cs}^{+}$ (1 $\mathrm{mM}$; data not shown), suggesting that neither voltage-gated $\mathrm{Ca}^{2+}$ currents nor $I_{\mathrm{h}}$ are required for its generation. A similar $\mathrm{Na}^{+}$-sensitive, $\mathrm{Ca}^{2+}$-insensitive mechanism drives spontaneous firing in other CNS pacemakers, including subthalamic neurons (Do and Bean, 2003), cerebellar Purkinje cells (Raman and Bean, 1999), and the dopaminergic retinal amacrine cell (Feigenspan et al., 1998).

RGCs have been found to express a variety of voltage-gated $\mathrm{Na}^{+}$channels that give rise to transient rapidly inactivating inward currents (Lipton and Tauck, 1987; Kaneda and Kaneko, 1991; Skaliora et al., 1993). Persistent $\mathrm{Na}^{+}$current is present in dissociated goldfish RGCs (Hidaka and Ishida, 1998) but has not been reported in mammalian retina. Our experiments show that mouse $\mathrm{ON}$ and OFF RGCs have $I_{\mathrm{NaP}}$ with amplitudes and voltage activation ranges that are similar to that found in many other types of neurons (Stafstrom et al., 1985; Pennartz et al., 1997; Hidaka and Ishida, 1998; Vervaeke et al., 2006). The identities of all of the channel types that give rise to $I_{\mathrm{NaP}}$ have not been established but are known to include $\mathrm{Na}_{\mathrm{V}} 1.1, \mathrm{Na}_{\mathrm{V}} 1.2$, and $\mathrm{Na}_{\mathrm{V}} 1.6$, with the last being the predominate channel in mature retina (Boiko et al., 2003; Van Wart and Matthews, 2006a). These studies, however, did not compare the spectrum of $\mathrm{Na}^{+}$channel expression in ON and OFF RGCs and cannot rule out the possibility that they express different mixtures of $\mathrm{Na}^{+}$channel subtypes.

A key factor in the differences in spontaneous activity between $\mathrm{ON}$ and OFF RGCs was the difference in $V_{\text {rest }}(-55 \mathrm{vs}-65 \mathrm{mV}$ in OFF and ON cells, respectively, in the presence of synaptic blockers and TTX). Thus, the persistent current is active and generates spontaneous spike activity at rest in OFF cells but not ON cells. The resting ("leak") current participates in this by positioning $V_{\text {rest }}$ within the activation range of $I_{\mathrm{NaP}}$ and other voltage-gated currents. The identity of neuronal leak channels is complex (Bayliss et al., 2003; Talley et al., 2003), and little is known about their expression in RGCs (Skaliora et al., 1995). 

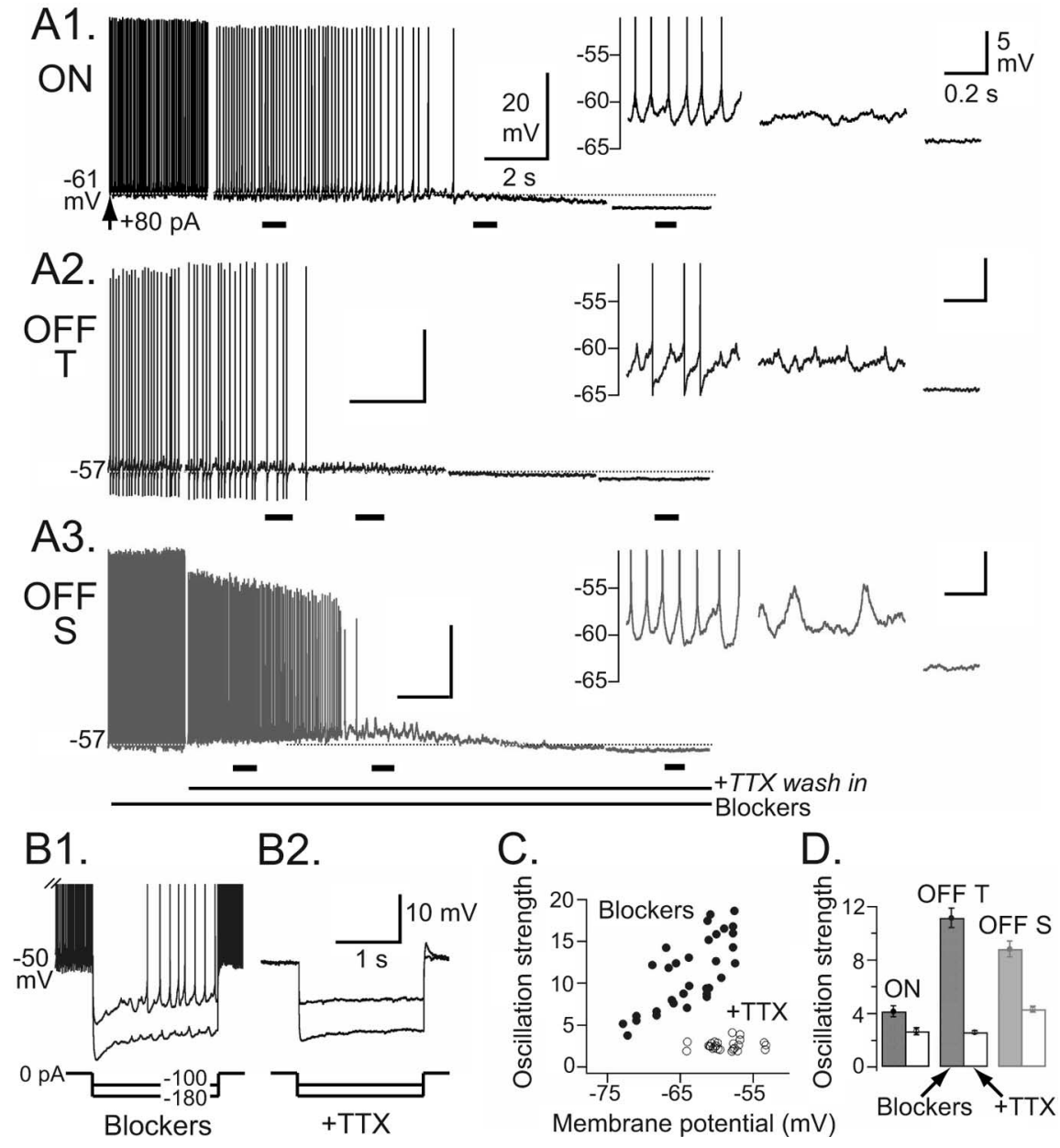

Figure 9. Spontaneous firing in OFF RGCs is driven by TTX-sensitive $\mathrm{Na}^{+}$current. $\boldsymbol{A}$, Whole-cell current-clamp recording of spontaneous firing from $0 \mathrm{~N}(\boldsymbol{A 1}), 0 \mathrm{FF} T(\boldsymbol{A 2})$, and OFF S (A3) RGCs during addition of $0.1 \mu \mathrm{M}$ TTX to the synaptic blocker mixture. The $0 \mathrm{~N}$ cell was first depolarized by $+80 \mathrm{pA}$ for comparison with OFF cells (arrow). Insets show segments of the voltage trace on an expanded timescale, as indicated by line segments under longer sweeps (left). Note that voltage oscillations persist for a short time after fast spikes are abolished and that TTX causes an $\sim 3-5 \mathrm{mV}$ overall hyperpolarization. $\boldsymbol{B}$, Reduction of subthreshold oscillations after TTX application. Responses to hyperpolarizing current injection from an OFF T cell before (B1) and after (B2) adding $0.1 \mu \mathrm{m} \mathrm{TTX}$ to the blocker mixture. Different cell than in $\boldsymbol{A}$. C, Plot of oscillation strength versus $V_{\mathrm{m}}$ for a collection of OFF T cells before and after TTX addition. $\boldsymbol{D}$, Effect of TTX on oscillation strength. Mean reduction was 35.8, 76.7, and 50.9\% for ON, OFF T, and OFF S RGCs, respectively. For values and statistical comparisons, see Table 2.

\section{Modulation of spontaneous activity by retinal circuitry}

The retina is an active circuit; photoreceptors and interneurons tonically release neurotransmitter in light and dark. How does this influence OFF cell spontaneous activity? In steady light under physiological conditions, OFF cell maintained firing is irregular but becomes highly regular in the absence of synaptic input (Fig. 3). This indicates that synaptic input is the source of the irregularity of spontaneous activity. OFF RGCs receive direct (postsynaptic) inhibition in steady light (Zaghloul et al., 2003) and during light responses (Pang et al., 2003; Zaghloul et al., 2003; Murphy and Rieke, 2006). Because inhibitory conductances are sufficient to modulate spiking in OFF RGCs (Murphy and Rieke, 2006), synaptic inhibition (which is noisy) would introduce variability into spontaneous spike trains. Presynaptic inhibition of glutamate release from OFF cone bipolar cell terminals is provided by AII amacrine cells (Bloomfield and Dacheux, 2001) and could also participate in modulating excitatory drive to OFF RGCs. However, OFF cells receive fivefold larger inhibitory than excitatory conductances (Murphy and Rieke, 2006), suggesting that direct postsynaptic inhibition would have a stronger influence than presynaptic modulation of excitatory input. Although our results do not evaluate the relative impact of synaptic and intrinsic mechanisms on firing, it is possible that postsynaptic inhibitory modulation of intrinsic spontaneous activity is sufficient to account for the resting activity of OFF RGCs under physiological conditions. A similar mechanism underlies the maintained firing of cerebellar cortex neurons, in which tonic inhibition converts regular spontaneous firing into irregular maintained discharge (Hausser and Clark, 1997). In this scenario, excitatory input is not required for resting activity but participates in generating light-evoked responses.

\section{Function of spontaneous activity}

A number of differences between $\mathrm{ON}$ and OFF retinal circuits have been described, including receptive field size, response kinetics, contrast sensitivity, contrast adaptation, presynaptic inhibition, and the dynamics of synaptic excitation and inhibition (Kim and Rieke, 2001; Chichilnisky and Kalmar, 2002; Pang et al., 2003; Zaghloul et al., 2003; Protti et al., 2005; Sagdullaev et al., 2006). These studies focused on circuitry presynaptic to RGCs. We find that ON and OFF retinal pathways can be distinguished by intrinsic differences in electrophysiological properties of RGCs, as well as differences in synaptic circuitry. In the following, we outline explanations for a role of spontaneous activity in resting and light-evoked activity.

Why is the resting discharge of $\mathrm{ON}$ and OFF pathways set by different mechanisms? One possibility is that the firing properties of RGCs reflect constraints imposed by presynaptic circuitry. Because maintained activity in ON cells depends on tonic glutamate input, steady-state basal release from presynaptic ON bipolar cells must be high. This is supported by experiments showing that increments and decrements in light around a steady mean modulate a single excitatory conductance in $\mathrm{ON}$ RGCs, suggesting that their mean spike rate is a direct reflection of steady glutamate input (Zaghloul et al., 2003). In this situation, active properties would not be required to maintain high rates of resting discharge. In OFF RGCs, basal glutamate input is low at moderate levels of light adaptation (Demb et al., 2001; Zaghloul et al., 2003). However, even at bright backgrounds when basal release from OFF bipolars would be expected to be at a minimum, the firing rate of OFF RGCs does not decrease accordingly (Rodieck and Smith, 1966; Rodieck, 1967; Barlow and Levick, 1969). In this situation, it is possible that spontaneous activity assumes a more prominent role, which could affect the relationship between firing rate and light intensity. This could account for differences in maintained firing at bright backgrounds between $\mathrm{ON}$ and OFF RGCs.

Intrinsic properties are likely to play a role in the production 
of the OFF cell light response. RGCs fire bursts of spikes in response to transient changes in light intensity, which has been explained by transient bursts of synaptic input (Pang et al., 2003; Freed, 2005). However, in OFF cells, the spike response to light may also be influenced by the intrinsic capacity of the cell for generating bursts of action potentials. Burst firing typically requires a hyperpolarizing prepulse to bring voltage-gated channels out of inactivation (Jahnsen and Llinas, 1984). If RGCs operate in this way, (1) they should contain low-threshold voltage-gated currents, (2) they should receive direct inhibition during a light response, and (3) inhibition should precede excitation. These criteria are met for OFF RGCs; they express T-type $\mathrm{Ca}^{2+}$ current, and their light responses are dominated by direct inhibitory conductances (inhibition/excitation ratio of 5:1) (Pang et al., 2003; Zaghloul et al., 2003; Murphy and Rieke, 2006), which precedes excitation by tens to hundreds of milliseconds (Murphy and Rieke, 2006). Thus, in addition to synaptic excitation, the burst of spike activity associated with the light response of OFF RGCs may be driven by the dynamics of synaptic inhibition in concert with the activation of the intrinsic conductances of the cell.

Our results show that differences in synaptic circuitry are not the only differences between the ON and OFF pathways. Instead, $\mathrm{ON}$ and OFF RGCs themselves have major differences in intrinsic properties, which may help to explain unresolved questions about $\mathrm{ON}$ and $\mathrm{OFF}$ retinal circuits.

\section{References}

Barlow HB, Levick WR (1969) Changes in the maintained discharge with adaptation level in the cat retina. J Physiol (Lond) 202:699-718.

Barlow HB, Levick WR, Yoon M (1971) Responses to single quanta of light in retinal ganglion cells of the cat. Vision Res Suppl 3:87-101.

Bayliss DA, Sirois JE, Talley EM (2003) The TASK family: two-pore domain background $\mathrm{K}^{+}$channels. Mol Interv 3:205-219.

Bloomfield SA, Dacheux RF (2001) Rod vision: pathways and processing in the mammalian retina. Prog Retin Eye Res 20:351-384.

Boiko T, Van Wart A, Caldwell JH, Levinson SR, Trimmer JS, Matthews G (2003) Functional specialization of the axon initial segment by isoformspecific sodium channel targeting. J Neurosci 23:2306-2313.

Bolz J, Wassle H, Thier P (1984) Pharmacological modulation of on and off ganglion cells in the cat retina. Neuroscience 12:875-885.

Chichilnisky EJ, Kalmar RS (2002) Functional asymmetries in ON and OFF ganglion cells of primate retina. J Neurosci 22:2737-2747.

Cowan RL, Wilson CJ (1994) Spontaneous firing patterns and axonal projections of single corticostriatal neurons in the rat medial agranular cortex. J Neurophysiol 71:17-32.

Crill WE (1996) Persistent sodium current in mammalian central neurons. Annu Rev Physiol 58:349-362.

Demb JB, Zaghloul K, Haarsma L, Sterling P (2001) Bipolar cells contribute to nonlinear spatial summation in the brisk-transient $(\mathrm{Y})$ ganglion cell in mammalian retina. J Neurosci 21:7447-7454.

Denk W, Detwiler PB (1999) Optical recording of light-evoked calcium signals in the functionally intact retina. Proc Natl Acad Sci USA 96:7035-7040.

Denk W, Strickler JH, Webb WW (1990) Two-photon laser scanning fluorescence microscopy. Science 248:73-76.

Do MT, Bean BP (2003) Subthreshold sodium currents and pacemaking of subthalamic neurons: modulation by slow inactivation. Neuron 39:109-120.

Euler T, Detwiler PB, Denk W (2002) Directionally selective calcium signals in dendrites of starburst amacrine cells. Nature 418:845-852.

Feigenspan A, Gustincich S, Bean BP, Raviola E (1998) Spontaneous activity of solitary dopaminergic cells of the retina. J Neurosci 18:6776-6789.

Freed MA (2005) Quantal encoding of information in a retinal ganglion cell. J Neurophysiol 94:1048-1056.

Frishman LJ, Levine MW (1983) Statistics of the maintained discharge of cat retinal ganglion cells. J Physiol (Lond) 339:475-494.

Granit R (1947) Sensory mechanisms of the retina. New York: Oxford UP.

Guenther E, Rothe T, Taschenberger H, Grantyn R (1994) Separation of calcium currents in retinal ganglion cells from postnatal rat. Brain Res 633:223-235.

Guenther E, Schmid S, Reiff D, Zrenner E (1999) Maturation of intrinsic membrane properties in rat retinal ganglion cells. Vision Res 39:2477-2484.

Harris-Warrick RM (2002) Voltage-sensitive ion channels in rhythmic motor systems. Curr Opin Neurobiol 12:646-651.

Hausser M, Clark BA (1997) Tonic synaptic inhibition modulates neuronal output pattern and spatiotemporal synaptic integration. Neuron 19:665-678.

Hausser M, Raman IM, Otis T, Smith SL, Nelson A, du Lac S, Loewenstein Y, Mahon S, Pennartz C, Cohen I, Yarom Y (2004) The beat goes on: spontaneous firing in mammalian neuronal microcircuits. J Neurosci 24:9215-9219.

Hidaka S, Ishida AT (1998) Voltage-gated $\mathrm{Na}^{+}$current availability after step- and spike-shaped conditioning depolarizations of retinal ganglion cells. Pflügers Arch 436:497-508.

Jahnsen H, Llinas R (1984) Electrophysiological properties of guinea-pig thalamic neurones: an in vitro study. J Physiol (Lond) 349:205-226.

Kaneda M, Kaneko A (1991) Voltage-gated sodium currents in isolated retinal ganglion cells of the cat: relation between the inactivation kinetics and the cell type. Neurosci Res 11:261-275.

Karschin A, Lipton SA (1989) Calcium channels in solitary retinal ganglion cells from post-natal rat. J Physiol (Lond) 418:379-396.

Kass RS, Tsien RW (1982) Fluctuations in membrane current driven by intracellular calcium in cardiac Purkinje fibers. Biophys J 38:259-269.

Kim KJ, Rieke F (2001) Temporal contrast adaptation in the input and output signals of salamander retinal ganglion cells. J Neurosci 21:287-299.

Kuffler SW, Fitzhugh R, Barlow HB (1957) Maintained activity in the cat's retina in light and darkness. J Gen Physiol 40:683-702.

Lee SC, Hayashida Y, Ishida AT (2003) Availability of low-threshold $\mathrm{Ca}^{2+}$ current in retinal ganglion cells. J Neurophysiol 90:3888-3901.

Lipton SA, Tauck DL (1987) Voltage-dependent conductances of solitary ganglion cells dissociated from the rat retina. J Physiol (Lond) 385:361-391.

Llinas R, Sugimori M (1980) Electrophysiological properties of in vitro Purkinje cell somata in mammalian cerebellar slices. J Physiol (Lond) 305:171-195.

Llinas R, Yarom Y (1981) Electrophysiology of mammalian inferior olivary neurones in vitro. Different types of voltage-dependent ionic conductances. J Physiol (Lond) 315:549-567.

Llinas RR (1988) The intrinsic electrophysiological properties of mammalian neurons: insights into central nervous system function. Science 242:1654-1664.

Masland RH (2001) The fundamental plan of the retina. Nat Neurosci 4:877-886.

Massey SC, Redburn DA, Crawford ML (1983) The effects of 2-amino-4phosphonobutyric acid (APB) on the ERG and ganglion cell discharge of rabbit retina. Vision Res 23:1607-1613.

Murphy GJ, Rieke F (2006) Network variability limits stimulus-evoked spike timing precision in retinal ganglion cells. Neuron 52:511-524.

Myhr KL, Lukasiewicz PD, Wong RO (2001) Mechanisms underlying developmental changes in the firing patterns of $\mathrm{ON}$ and OFF retinal ganglion cells during refinement of their central projections. J Neurosci 21:8664-8671.

Neher E (1992) Correction for liquid junction potentials in patch clamp experiments. Methods Enzymol 207:123-131.

Nelson R, Kolb H (2004) ON and OFF pathways in the vertebrate retina and visual system. In: The visual neurosciences (Chalupa LM, Werner JS, eds), pp 260-278. Cambridge, MA: MIT.

O'Brien BJ, Isayama T, Richardson R, Berson DM (2002) Intrinsic physiological properties of cat retinal ganglion cells. J Physiol (Lond) 538:787-802.

Packer O, Diller LC, Verweij J, Lee BB, Pokorny J, Williams DR, Dacey DM, Brainard DH (2001) Characterization and use of a digital light projector for vision research. Vision Res 41:427-439.

Pang JJ, Gao F, Wu SM (2003) Light-evoked excitatory and inhibitory synaptic inputs to ON and OFF $\alpha$ ganglion cells in the mouse retina. J Neurosci 23:6063-6073.

Pennartz CM, Bierlaagh MA, Geurtsen AM (1997) Cellular mechanisms underlying spontaneous firing in rat suprachiasmatic nucleus: involve- 
ment of a slowly inactivating component of sodium current. J Neurophysiol 78:1811-1825.

Petersen CC, Hahn TT, Mehta M, Grinvald A, Sakmann B (2003) Interaction of sensory responses with spontaneous depolarization in layer $2 / 3$ barrel cortex. Proc Natl Acad Sci USA 100:13638-13643.

Powers RK, Binder MD (2003) Persistent sodium and calcium currents in rat hypoglossal motoneurons. J Neurophysiol 89:615-624.

Protti DA, Flores-Herr N, Li W, Massey SC, Wassle H (2005) Light signaling in scotopic conditions in the rabbit, mouse and rat retina: a physiological and anatomical study. J Neurophysiol 93:3479-3488.

Raman IM, Bean BP (1999) Ionic currents underlying spontaneous action potentials in isolated cerebellar Purkinje neurons. J Neurosci 19:1663-1674.

Rodieck RW (1967) Maintained activity of cat retinal ganglion cells. J Neurophysiol 30:1043-1071.

Rodieck RW, Smith PS (1966) Slow dark discharge rhythms of cat retinal ganglion cells. J Neurophysiol 29:942-953.

Sagdullaev BT, McCall MA (2005) Stimulus size and intensity alter fundamental receptive-field properties of mouse retinal ganglion cells in vivo. Vis Neurosci 22:649-659.

Sagdullaev BT, McCall MA, Lukasiewicz PD (2006) Presynaptic inhibition modulates spillover, creating distinct dynamic response ranges of sensory output. Neuron 50:923-935.

Sakmann B, Creutzfeldt OD (1969) Scotopic and mesopic light adaptation in the cat's retina. Pflügers Arch 313:168-185.

Sanchez-Vives MV, McCormick DA (2000) Cellular and network mechanisms of rhythmic recurrent activity in neocortex. Nat Neurosci 3:1027-1034.

Schiller PH (1992) The ON and OFF channels of the visual system. Trends Neurosci 15:86-92.

Schiller PH, Sandell JH, Maunsell JH (1986) Functions of the ON and OFF channels of the visual system. Nature 322:824-825.

Shadlen MN, Newsome WT (1998) The variable discharge of cortical neurons: implications for connectivity, computation, and information coding. J Neurosci 18:3870-3896.

Skaliora I, Scobey RP, Chalupa LM (1993) Prenatal development of excitability in cat retinal ganglion cells: action potentials and sodium currents. J Neurosci 13:313-323.

Skaliora I, Robinson DW, Scobey RP, Chalupa LM (1995) Properties of K ${ }^{+}$ conductances in cat retinal ganglion cells during the period of activitymediated refinements in retinofugal pathways. Eur $\mathrm{J}$ Neurosci $7: 1558-1568$

Slaughter MM, Miller RF (1981) 2-amino-4-phosphonobutyric acid: a new pharmacological tool for retina research. Science 211:182-185.

Stafstrom CE, Schwindt PC, Chubb MC, Crill WE (1985) Properties of persistent sodium conductance and calcium conductance of layer $\mathrm{V}$ neurons from cat sensorimotor cortex in vitro. J Neurophysiol 53:153-170.
Surmeier DJ, Mercer JN, Chan CS (2005) Autonomous pacemakers in the basal ganglia: who needs excitatory synapses anyway? Curr Opin Neurobiol 15:312-318.

Tabata T, Ishida AT (1996) Transient and sustained depolarization of retinal ganglion cells by Ih. J Neurophysiol 75:1932-1943.

Tabata T, Kano M (2002) Heterogeneous intrinsic firing properties of vertebrate retinal ganglion cells. J Neurophysiol 87:30-41.

Taddese A, Bean BP (2002) Subthreshold sodium current from rapidly inactivating sodium channels drives spontaneous firing of tuberomammillary neurons. Neuron 33:587-600.

Talley EM, Sirois JE, Lei Q, Bayliss DA (2003) Two-pore-domain (KCNK) potassium channels: dynamic roles in neuronal function. Neuroscientist 9:46-56.

Tolhurst DJ, Movshon JA, Thompson ID (1981) The dependence of response amplitude and variance of cat visual cortical neurones on stimulus contrast. Exp Brain Res 41:414-419.

Traub RD, Buhl EH, Gloveli T, Whittington MA (2003) Fast rhythmic bursting can be induced in layer $2 / 3$ cortical neurons by enhancing persistent $\mathrm{Na}^{+}$conductance or by blocking BK channels. J Neurophysiol 89:909-921.

Van Wart A, Matthews G (2006a) Expression of sodium channels Nav1.2 and Nav1.6 during postnatal development of the retina. Neurosci Lett 403:315-317.

Van Wart A, Matthews G (2006b) Impaired firing and cell-specific compensation in neurons lacking nav1.6 sodium channels. J Neurosci 26:7172-7180.

Vervaeke K, Hu H, Graham LJ, Storm JF (2006) Contrasting effects of the persistent $\mathrm{Na}^{+}$current on neuronal excitability and spike timing. Neuron 49:257-270.

Wang GY, Ratto G, Bisti S, Chalupa LM (1997) Functional development of intrinsic properties in ganglion cells of the mammalian retina. J Neurophysiol 78:2895-2903.

Wang GY, Robinson DW, Chalupa LM (1998) Calcium-activated potassium conductances in retinal ganglion cells of the ferret. J Neurophysiol 79:151-158.

Wassle H (2004) Parallel processing in the mammalian retina. Nat Rev Neurosci 5:747-757.

Wassle H, Schafer-Trenkler I, Voigt T (1986) Analysis of a glycinergic inhibitory pathway in the cat retina. J Neurosci 6:594-604.

Werblin FS, Dowling JE (1969) Organization of the retina of the mudpuppy, Necturus maculosus. II. Intracellular recording. J Neurophysiol 32:339-355.

Zaghloul KA, Boahen K, Demb JB (2003) Different circuits for ON and OFF retinal ganglion cells cause different contrast sensitivities. J Neurosci 23: 2645-2654. 